\title{
Caracterização e estrutura de quintais agroflorestais na Comunidade Piranhas Velha no Município de São José de Piranhas, Estado da Paraíba, Nordeste do Brasil
}

\section{José Luciano Andrade da Silva, José Deomar de Souza Barros, Jânio Trajano de Araújo, Rafael da Silva Moreira e Alexson Vieira Pordeus}

Universidade Federal de Campina Grande (UFCG). Centro de Formação de Professores. Grupo de Pesquisa Ambiental para o Desenvolvimento do Semiárido (GPA). Rua Sérgio Moreira de Figueiredo, s/no․ Casas Populares. Cajazeiras-PB, Brasil (58900-000). E-mail: deomarbarros@gmail.com.

Resumo. Os quintais agroflorestais têm se tornado uma das características das regiões semiáridas em virtude dos sérios problemas de concentração de renda, sendo útil nos sistemas agrícolas de base familiar. A presente pesquisa foi realizada na Comunidade Rural de Piranhas Velha no Município de São José de Piranhas, no Sertão paraibano, e teve como objetivo caracterizar os quintais agroflorestais na Comunidade Rural de Piranhas Velha, no Município de São José de Piranhas, Estado da Paraíba, Nordeste do Brasil. A pesquisa foi realizada nos meses de maio a setembro de 2016, onde foram aplicados 20 questionários na forma de entrevistas em visitas feitas na comunidade. Os resultados obtidos apresentaram a diversidade vegetal e animal que são utilizados no hábito alimentar, que tem contribuído economicamente para subsistência em consequência da baixa renda. A comunidade pesquisada apresenta interesse pela agricultura em que $90 \%$ dos entrevistados e, mesmo com a escassez de água e a falta de assistência, demonstraram níveis alto e médio de satisfação com o seu quintal. Estes resultados apontam as necessidades de sensibilização e intervenção do poder público e da sociedade civil organizada acerca da estrutura dos quintais agroflorestais e de suas condições socioeconômicas e ambientais, possibilitando uma reflexão crítica das práticas de manejo adotadas na localidade.

Palavras-chave: Biodiversidade; Semiárido; Condições socioeconômicas; Manejo agroflorestal; Etnoconhecimento.

Abstract. Characterization and structure of agro-forest properties in the District of Piranhas Velha in the Municipality
Recebido

$23 / 08 / 2019$

Aceito

$30 / 11 / 2019$

Disponível on line

01/12/2019

Publicado

31/12/2019

Acesso aberto

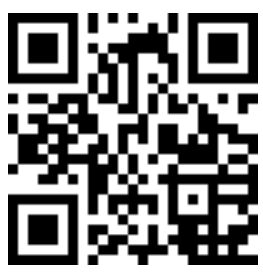

ORCID

(ㄱ) 0000-0001-6840-1052 José Luciano Andrade da Silva

(1) 0000-0003-3785-9823 José Deomar de Souza Barros 
of São José de Piranhas, State of Paraíba, Brazil. Agroforest backyards have become one of the characteristics of semi-arid regions because of the serious problems of income concentration, and being predominantly used in family-based agricultural systems. This research was carried out in District of Piranhas Velha, in the Municipality of São José de Piranhas, located in the Paraíba State. Its objective is to characterize the agroforestry backyards of the Rural Community of Piranhas Velha, São José de Piranhas, State of Paraíba, Northeast Brazil. The research was carried out in May to September 2016, in which 20 questionnaires were applied through interview forms distributed in the mentioned in the community of aforementioned study area. The results obtained showed a large variaty of vegetables and animals that are used in the food habit, which has contributed economically to subsistence as a result of low income. The surveyed community has an interest in agriculture, in which $90 \%$ of interviewees, even though water and assistance scarcity, demonstrated high levels of satisfaction with their backyards. These results show the need for awareness and intervention by the public authorities intervention and organized civil society concerning the structure of agroforest backyards reflecting about socioeconomic and environmental conditions that may allow a critical reflection concerning the management practices adopted in the studied area.

Keywords: Biodiversity; Semi-arid; Socioeconomic conditions; Management; Ethno-knowledge.

\section{Introdução}

Os quintais agroflorestais (QAF) são definidos por pequenas áreas de terra utilizadas geralmente por um grupo familiar para a plantação e criação de animais próximos às residências, sejam rurais, periurbanas e urbanas, implantadas nas áreas contiguas as residências, ou seja, o quintal. Os QAF são formados por várias espécies agrícolas e florestais, onde são criados pequenos animais domésticos ou domesticados (Chitsondzo e Silva, 2013; Almeida e Gama, 2014; Damaceno e Lobato, 2019; Santos et al., 2019). Diante das necessidades e qualidade de vida das famílias, os quintais proporcionam benefícios econômicos e podem ser considerados como sustentável ao longo dos anos, pois oferta uma série de produtos e/ou serviços, diminuindo de forma considerável os gastos das famílias com os produtos de subsistência (Pinto, 2012; Vieira et al., 2012).

\author{
D) 0000-0002-5491-9632 \\ Jânio Trajano de \\ Araújo \\ (ㄱ) 0000-0002-7203-2699 \\ Rafael da Silva \\ Moreira \\ () 0000-0002-5596-7759 \\ Alexson Vieira \\ Pordeus
}

Criados, na maioria das vezes, para suprir a necessidade de produção agrícola, os quintais agroflorestais pode ser considerado ainda como conservadores da biodiversidade, por conta das diversas formas de sistemas produtivos, e da diversidade vegetal presente nos quintais. Apesar das dificuldades encontradas principalmente na infraestrutura, a necessidade da produção para subsistência da família faz com que no entorno de suas casas se encontre uma diversidade significativa de plantas destinadas ao consumo da família e animais domésticos (Gomes, 2010; Gonçalves e Lucas, 2017).

Os quitais agroflorestais podem ser considerados uma estratégia sustentável de convivência com o semiárido brasileiro, tendo em vista que pode se constituir uma alternativa viável para o pequeno produtor, especialmente as mulheres que geralmente ficam responsáveis pelo manejo do quintais, Os quintais são uma fonte de renda e subsistência, uma prática 
tradicional no semiárido brasileiro (Freitas, 2008; Laranjeira et al., 2015; Silva et al., 2018).

Faz-se necessário que os quintais estejam bem estruturados e funcionem de forma adequada, por meio de um manejo conservacionista, uso de ferramentas adequadas, adubação com orientação técnica e controle de pragas. Isto exige do produtor capacitação para escolha do modelo de exploração de forma a garantir sua sustentabilidade ao longo dos anos. Assim o presente estudo teve por objetivo caracterizar os quintais agroflorestais na Comunidade Rural de Piranhas Velha, no Município de São José de Piranhas, Estado da Paraíba, Nordeste do Brasil.

\section{Metodologia}

Caracterização da área de estudo

A Comunidade Rural Piranhas Velha está localizada no Município de São José de Piranhas, Estado da Paraíba, nas margens do Açude Engenheiro Ávidos, conhecido como Boqueirão, onde antes era Jatobá, que, após a construção do açude, teve a cidade alagada e reconstruída um pouco ao sul a $12 \mathrm{~km}$ recebendo o nome de São José de Piranhas, distando cerca de 503 km de João Pessoa.

De acordo com o CPRM (2005), o Município de São José de Piranhas apresenta uma população estimada em 19.956 habitantes, apresenta área territorial de $677,305 \mathrm{~km}^{2}$, apresentando as coordenadas geográficas de referência $7^{\circ} 7^{\prime} 5^{\prime \prime}$ de latitude sul e $38^{\circ} 30^{\prime} 5^{\prime \prime}$ de longitude oeste, e temperatura média $25,7^{\circ} \mathrm{C}$ (IBGE, 2010).

\section{Classificação da pesquisa}

Para a classificação da pesquisa, tomou-se como base a metodologia adotada por Silva e Menezes (2005). Do ponto de vista da natureza a pesquisa é classificada como aplicada, em que se refere a conhecimentos para aplicação práticas dirigidas à solução de problemas específicos. Quanto à forma de abordagem a pesquisa é classificada como quantitativa que significa traduzir em números opiniões e informações para classificá-las e analisálas, e qualitativa a qual busca uma compreensão detalhada dos significados e características situacionais apresentadas pelos entrevistados. Do ponto de vista de seus objetivos a pesquisa pode ser classificada como descritiva, a qual envolve levantamento bibliográfico; entrevistas com pessoas que habitam a comunidade da área de estudo; com relação aos procedimentos técnicos constituiu-se de um estudo de caso, estudo empírico que investiga um fenômeno atual dentro do seu contexto de realidade, dependem da perseverança, criatividade e raciocínio crítico do investigador para construir descrições, interpretações, enfim, explicações originais que possibilitem a extração cuidadosa de conclusões e recomendações.

\section{Sujeitos da pesquisa}

Foram selecionados atores sociais que desenvolvam práticas de quintais agroflorestais na comunidade. A importância destes atores está no fato deles possuírem experiências pessoais e conhecimento de causa sobre a temática da investigação. Esta pesquisa foi aprovada pelo Comitê de Ética em Pesquisa (CEP), CAAE 53965616.9.0000.5575.

\section{Amostra e amostragem}

A pesquisa foi realizada com famílias que residem na área de estudo, dos quais foram entrevistadas 20 famílias que possuem quintais agroflorestais. Foram incluídas no estudo as famílias que aceitaram participar voluntariamente e que tinham um adulto no domicílio para responder aos questionamentos.

\section{Instrumentos de coleta de dados}

A coleta de informações foi feita entre maio e setembro de 2016, por meio de registro com a utilização de questionários e entrevistas. Para isto foi utilizado à transcrição manual dos depoimentos e gravação em áudio para transcrição posterior. 


\section{Análise dos dados}

Os quintais agroflorestais foram avaliados utilizando-se alguns critérios, como, técnicas de manejo, condições socioeconômicas, estrutura e condições ambientais, ao final da análise dos dados foram utilizadas porcentagens, no intuito de verificar quais as melhores maneiras de cuidar dos quintais e as dificuldades encontradas pelos produtores, como também a importância e diversidade de vidas neles existentes. Após coletados, os dados foram implantados em uma planilha eletrônica para obtenção da frequência relativa, fornecendo dados da profissão, tamanho do quintal e uso de insumos externos em porcentagens, posteriormente foram elaborados gráficos.

\section{Resultados e discussão}

Foram entrevistadas 20 pessoas, em que cada uma representava uma família, sendo 12 do sexo masculino e oito do sexo feminino. Quanto à escolaridade (65\%) afirmou possuir fundamental I incompleto, (10\%) fundamental II incompleto, (5\%) ensino médio completo, $(10 \%)$ ensino médio incompleto e $(10 \%)$ não alfabetizados. Apesar de a maioria apresentar nível de escolaridade baixa, a maior parte é alfabetizada, muitos relataram ter participado do Programa Brasil Alfabetizado oferecido na comunidade.

Resultado diferente do encontrado por Barros et al. (2014) no diagnóstico socioeconômico na micro Bacia Hidrográfica do Riacho Val Paraíso, Estado da Paraíba, com relação ao nível de escolaridade foi observado que $47,1 \%$ dos produtores eram analfabetos.

Os entrevistados apresentaram idade entre 20 e 68 anos, tendo em média 45,7 anos. Apesar de todos se dedicarem à prática de cuidar dos quintais agroflorestais em suas residências, 55\% tem como profissão somente a agricultura, e parte desenvolvem outras atividades, como pescador, pedreiro e trabalhos domésticos (Figura 1).

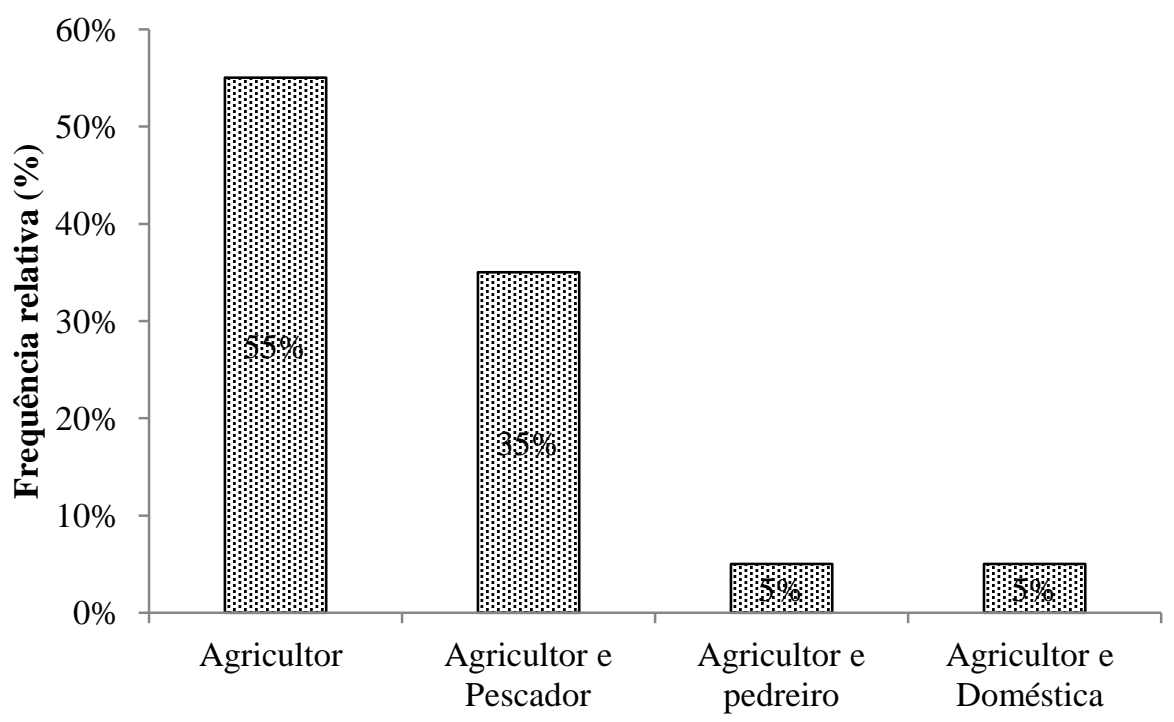

Figura 1. Profissão dos mantenedores dos quintais agroflorestais na Comunidade Piranhas Velha, Município de São José de Piranhas, Estado da Paraíba.

Estes resultados são semelhantes ao encontrado por Pinto (2012) quando pesquisou a agrobiodiversidade de quintais agroflorestais urbanos e perfil 
social de etnias indígenas em São Gabriel da Cachoeira, no Estado do Amazonas, e $58 \%$ dos entrevistados afirmou ter como profissão somente a agricultura.

0 número de pessoas por família variou entre 1 e 6 , tendo em média 3 pessoas/residência. Com relação ao número de pessoas que ajudam a cuidar do quintal variou de 1 a 3 , sendo na maioria das vezes o casal, marido e esposa, os responsáveis com trabalho diário variando entre $0,5 \mathrm{~h}$ e $3 \mathrm{~h}$, tendo média de $2 \mathrm{~h}$ por dia.

Foi verificado que na maioria das vezes apenas o casal é responsável no cuidado com o quintal. Segundo relato dos entrevistados o principal motivo deve-se ao fato de que os filhos estudam ou desenvolvem outra profissão. Resultado semelhante ao encontrado por Gervazio (2015) ao pesquisar a Agrobiodiversidade e qualidade do solo em quintais agroflorestais urbanos na Cidade de Alta Floresta, Mato Grosso, que também encontrou como média do número de membros de duas a três pessoas por domicílios.

A renda para maioria das famílias provém de auxílios governamentais, de outras profissões que exercem e do próprio quintal, que somando varia de $\mathrm{R} \$ 540,00$ a $\mathrm{R} \$ 1.760,00$ reais mensalmente, com uma média de $\mathrm{R} \$$ 842,00 por família. Apenas oito famílias adquirem renda proveniente do quintal, que varia entre $R \$ 60,00$ e $R \$ 500,00$ reais, com média de $R \$ 266,25$ reais por família. Salim (2012) destaca que apesar dos quintais contribuírem na alimentação e renda familiar, alguns proprietários exercem outras profissões como, pesca e agricultura, entre outras, e ainda parte deles recebem auxílio governamentais, como bolsa família e aposentadoria, o que permite satisfazer as necessidades básicas da família.

Levando em conta o tempo de atividades agropecuárias nas proximidades de suas residências, o tempo variou de 2 a 30 anos, tendo média de 11 anos de atividades, ocupando um espaço variando $60 \mathrm{~m}^{2}$ a $960 \mathrm{~m}^{2}$ de terra, com média de $244,75 \mathrm{~m}^{2}$ de terras. Sendo que $45 \%$ das famílias dizem permanecerem com 0 quintal do mesmo tamanho, outros dizem já ter tido o quintal maior ou menor, os que afirmaram ter diminuído o tamanho do quintal justificaram a escassez de água, assim como a falta de orientação e assistência técnica (Figura 2).

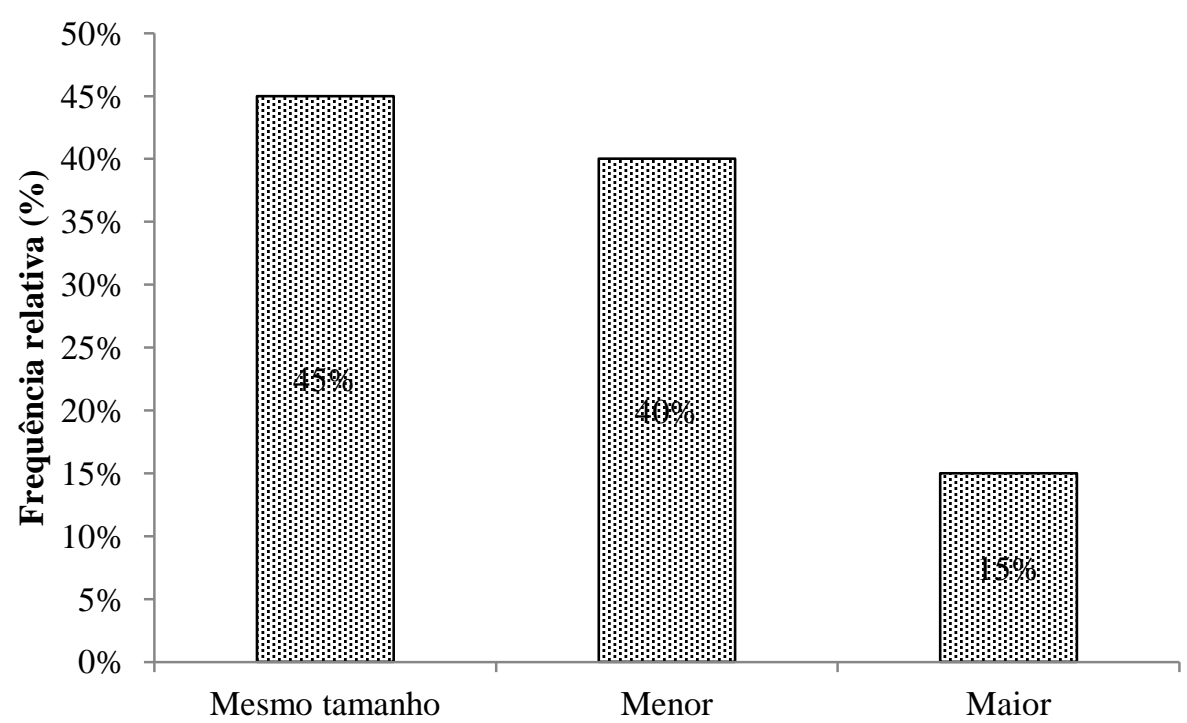

Figura 2. Frequência relativa do tamanho do quintal durante sua ocupação. 
Segundo Araújo et al. (2017) o maior desafio para o desenvolvimento socioeconômico e ambiental do Semiárido não é somente a irregularidade pluviométrica, mas também a insuficiência de políticas voltadas para disponibilização de infraestrutura hídrica, capaz de amenizar a escassez de água nos períodos de estiagem e a ineficiência na orientação técnica profissional às famílias que utilizam técnicas agrícolas como quintais agroflorestais.

Os que dizem que o seu quintal já foi maior e hoje está menor, reclamam ter sido pela dificuldade de conseguir água para desenvolver suas atividades agropecuárias em decorrência da escassez hídrica na região. E os que permanecem do mesmo tamanho já tinham acesso à água de poços tubulares. Segundo eles, somente as chuvas que vêm sendo distribuídas nos últimos anos naquela região não teriam como permanecer com o quintal do mesmo tamanho.

Das 20 famílias entrevistadas, apenas uma já possuía o quintal estabelecido, e diz permanecer as mesmas espécies, sendo motivo principal a falta de água.

Com relação ao uso do quintal, 5\% utilizam o quintal como área de lazer, criação de animais, plantio agrícola e plantio de espécies medicinais, $5 \%$ como criação de animais e plantio de espécies medicinais, 5\% como criação de animais, $5 \%$ como plantio de espécies medicinais, $10 \%$ plantio agrícola, $30 \%$ como criação de animais, plantio agrícola e plantio de espécies medicinais, $40 \%$ criação de animais e plantio agrícola.

0 uso do quintal para cultivo agrícola e criação de animais foi registrado em quase todos os questionários aplicados, sendo também utilizado para outras finalidades como lazer, sendo uso exclusivo dos moradores. Esses números são semelhantes aos encontrados por Salim (2012) em um estudo sobre quintais agroflorestais em área de terra-firme na terra indígena Kwatá-Laranjal, Amazonas, que mostrou a presença de cultivo agrícola e criação de animais em todos os quintais para sustentabilidade das famílias.

Foi verificado também o cultivo de plantas medicinais (Figura 3) nos quintais avaliados. Esta prática é relevante tendo em vista o baixo custo de produção e a manutenção dos conhecimentos tradicionais da população local, favorecendo assim o etnoconhecimento dos moradores locais em relação às técnicas de manejo e usos dessas plantas, corroborando com Sousa et al. (2014).

\section{Produção}

Com relação à produção, 100\% das famílias consomem parte do que é produzido no quintal, $50 \%$ das famílias fazem a troca de uma parte com vizinhos e familiares, $25 \%$ das famílias doam parte para vizinhos e $35 \%$ das famílias comercializam parte da produção. Sendo que $70 \%$ da produção são utilizadas no consumo, 24,75\% para comercialização e $5,25 \%$ para consumo animal. Conforme Gomes (2010), a maioria dos quintais destina a produção para subsistência, deixando uma menor quantidade para comercialização e consumo animal, mas que ainda tem mostrado uma alternativa de renda.

Quanto à distribuição do cultivo de plantas no quintal, $25 \%$ dos entrevistados selecionam uma parte da terra para o cultivo do milho, feijão e fava que acontece todos os anos na época chuvosa. Para a seleção e armazenamento das sementes/mudas existem algumas técnicas as quais irão garantir a próxima safra, a seleção acontece mais pela experiência, observando a qualidade, a principal delas, e se não estão contaminadas por algum tipo de praga. Já para o armazenamento, as sementes são colocadas em garrafas pet, uma maneira de proteger dos insetos, e as mudas são colocadas em um local à parte separada dos animais, onde são plantadas em um recipiente apropriado adubado na maioria das vezes com esterco de animal (Figura 4). Resultado semelhante ao de Gomes (2010) no estudo sobre os quintais agroflorestais no Município de Irati, Estado 
do Paraná, agrobiodiversidade sustentabilidade socioeconômica ambiental, onde mostrou que e armazenamento de mudas e sementes garante a qualidade do material, assegurando a próxima safra.
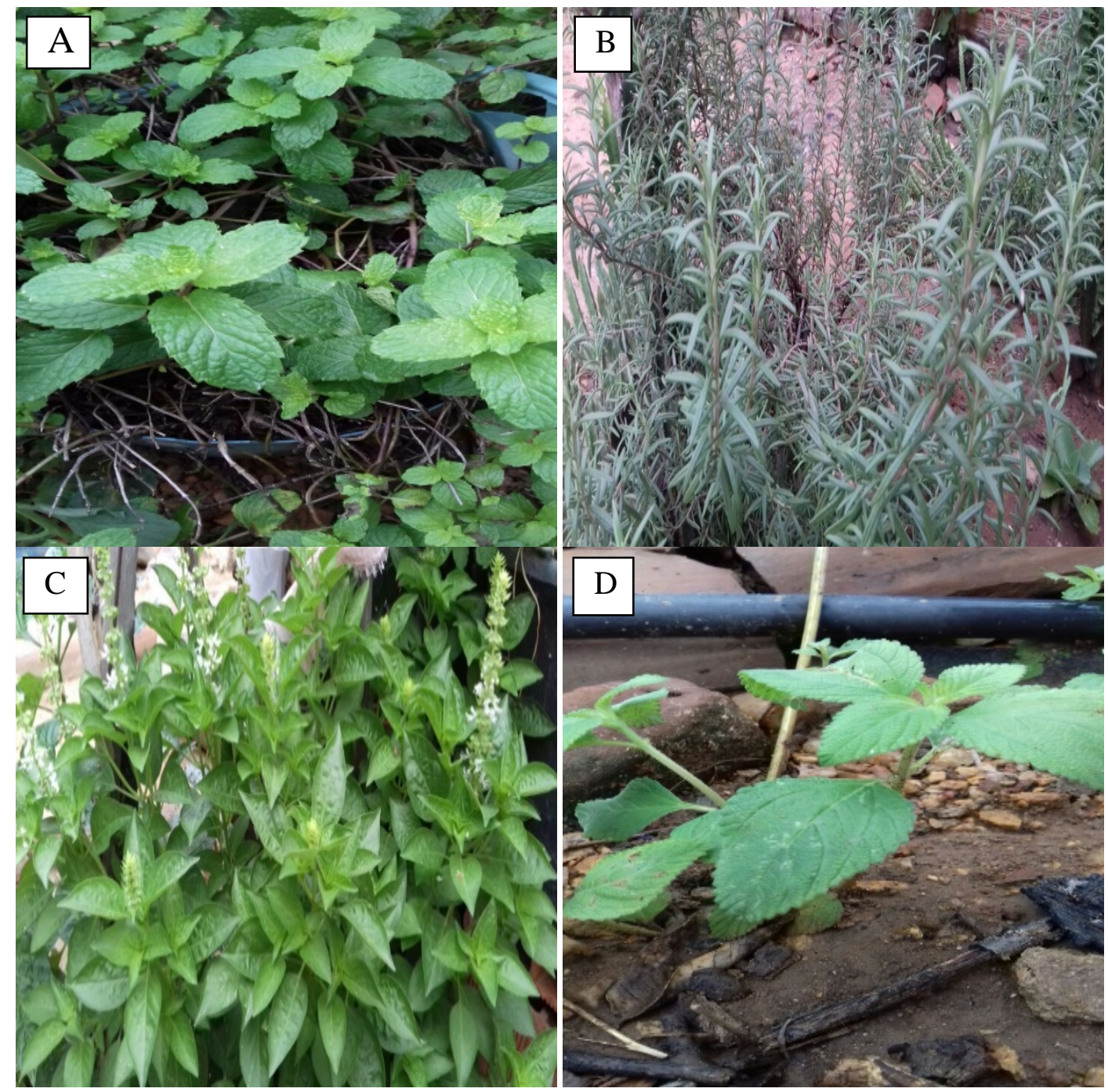

Figura 3. Cultivo de plantas medicinais. anador (A), alecrim (B), manjericão (C) e erva cidreira (D).

Ao estudar os aspectos funcionais e estruturais dos quintais, pode-se observar de forma semelhante que as plantações estão localizadas junto às residências, precisamente nos fundos dos terrenos.

Para adquirir as mudas/sementes, existem algumas viabilidades: com um parente, vizinho, amigo, próprio quintal, compra na cidade ou através da Empresa de Assistência Técnica e Extensão Rural
(EMATER), o que tem sido comum em outros trabalhos, como no diagnóstico realizado por Pinto (2012), em são Gabriel da Cachoeira, no Estado do Amazonas.

\section{Percepção acerca do quintal}

Os proprietários informaram que o quintal tem contribuído muito na comunidade, como: renda familiar, produto de qualidade, área de lazer, plantio 
agrícola, criação de animais, plantações de ervas medicinais e troca de produtos com familiares e vizinhos.

Os entrevistados denominam o espaço em que é cultivado nas proximidades de casa para autoconsumo como quintal, apenas um acrescentou: "uns dizem quintal e outros dizem chácara".
Resultado semelhante foi encontrado por Beretta (2010) na sua pesquisa, sobre a flora dos quintais agroflorestais de Ibiraquera, Imbituba, Estado de Santa Catarina, expressões ambientais e culturais, em que os termos usualmente utilizados pelos entrevistados foram quintal, chácara e terreiro.
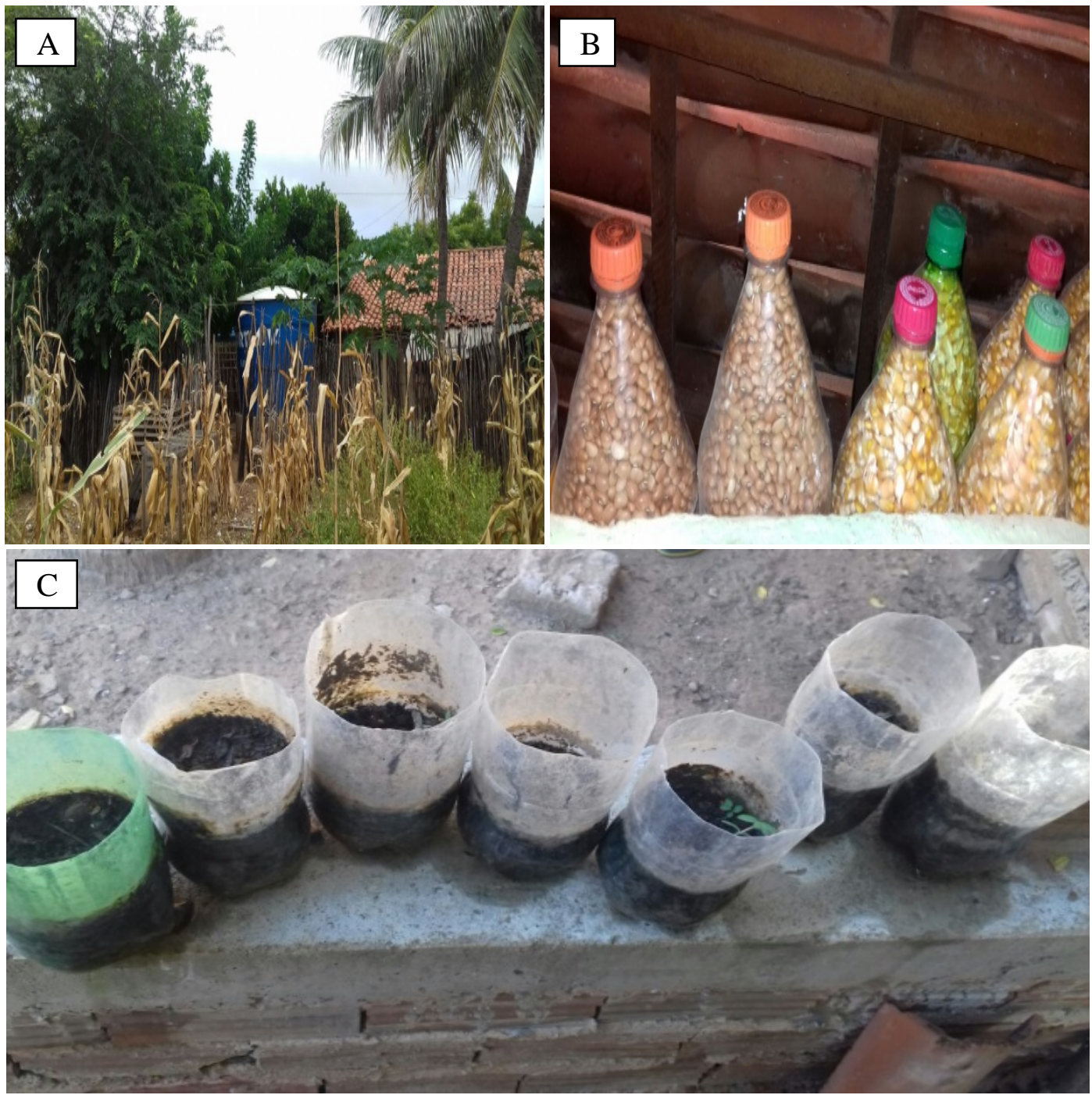

Figura 4. Delimitação de parte do quintal para parte do cultivo que acontece todos os anos (A); Sementes selecionadas para o próximo cultivo (B); Ambiente reservado para as mudas separada dos animais (C).

Apesar dos agricultores locais apresentarem interesse pela agricultura, não existe nenhum tipo de assistência técnica que possam contribuir com as famílias na estruturação dos quintais agroflorestais o que poderia ampliar suas fontes de suprimento alimentar e medicinal. Mesmo assim, a maioria dos 
proprietários (90\%) mostrou níveis alto e médio de satisfação com o seu quintal, mesmo variando em diferentes épocas do ano (verão e inverno), por uma ou outra razão, níveis baixo de satisfação foram observados em apenas 10\% dos quintais, motivo este que questionavam a escassez de água. Estes resultados são semelhantes aos encontrados por Gomes (2010) que ao pesquisar no município de Irati-Paraná a maioria dos proprietários $85 \%$ mostrou níveis médios e altos de satisfação com o seu quintal, embora essa percepção varie muito de acordo com a época do ano.

\section{As "lidas" no quintal}

As sementes/mudas são plantadas de formas diferentes, os entrevistados responderam que as sementes são plantadas no inverno, mais provável nos meses de janeiro, após a terra ser gradeada ou arada. Para plantar as sementes se utiliza um cavador ou uma enxada para fazer as covas, ou ainda, utiliza-se uma máquina manual que possui um registro que controla o número de grãos semeados. A Figura 5 mostra como as mudas são plantadas, em covas com as seguintes dimensões $40 \times 40 \times 40 \mathrm{~cm}$ (largura $\mathrm{x}$ comprimento $\mathrm{x}$ profundidade), podendo variar em caso de mudas menores, essas covas são adubadas uns três dias antes com uma mistura de terra e esterco animal.

Para proteger os cultivos do quintal dos animais, $50 \%$ dos proprietários utilizam cercas com telas de arames, 5\% com tábuas, $35 \%$ com cercas de varas e $10 \%$ não criam animais. $\mathrm{E}$ por isso não existe nenhum dano causado por animal no quintal (Figura 6). Estes resultados são diferentes dos encontrados por Chitsondzo e Silva (2013) em um estudo que tinha como objetivo caracterizar e avaliar os quintais caseiros em Machipanda, Distrito de Manica (Moçambique), em que na sua pesquisa foram utilizados cercas de arames farpados para o confinamento de alguns animais, enquanto outros eram criados soltos.

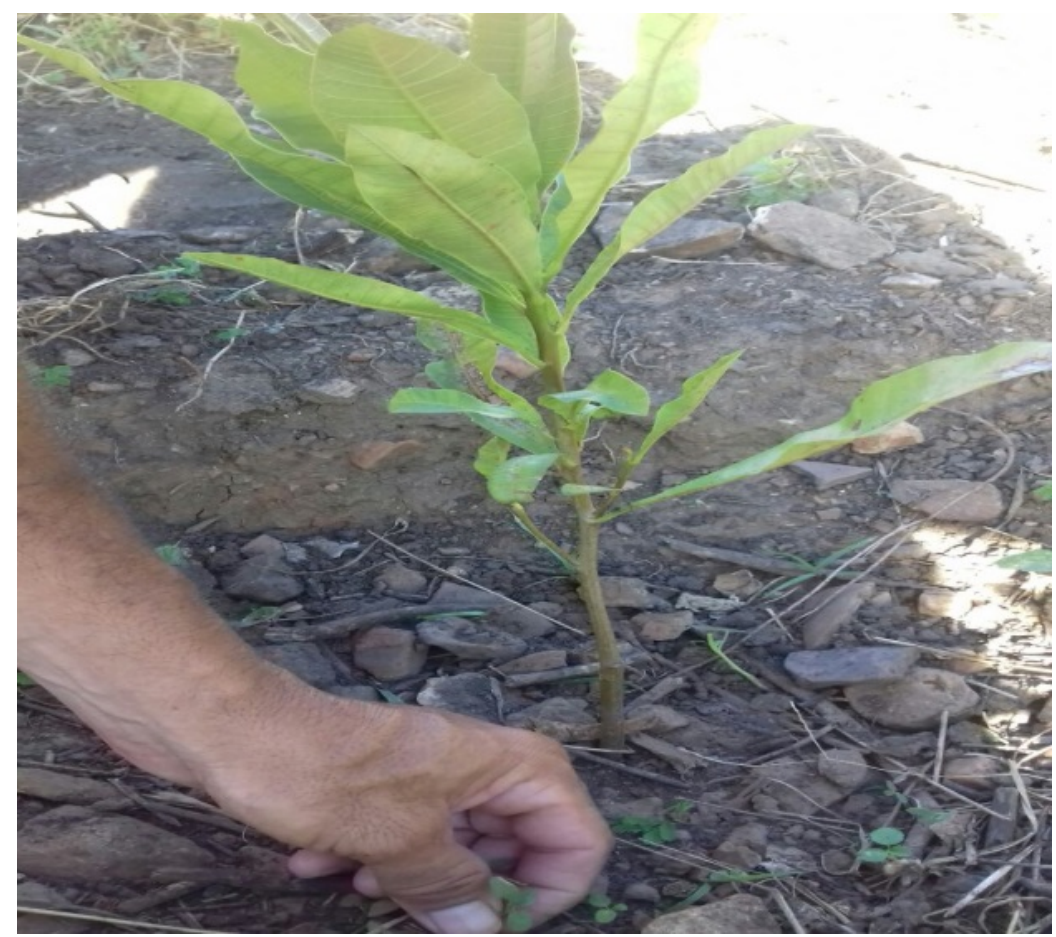

Figura 5. Muda de caju em cova permanente após adubação. 

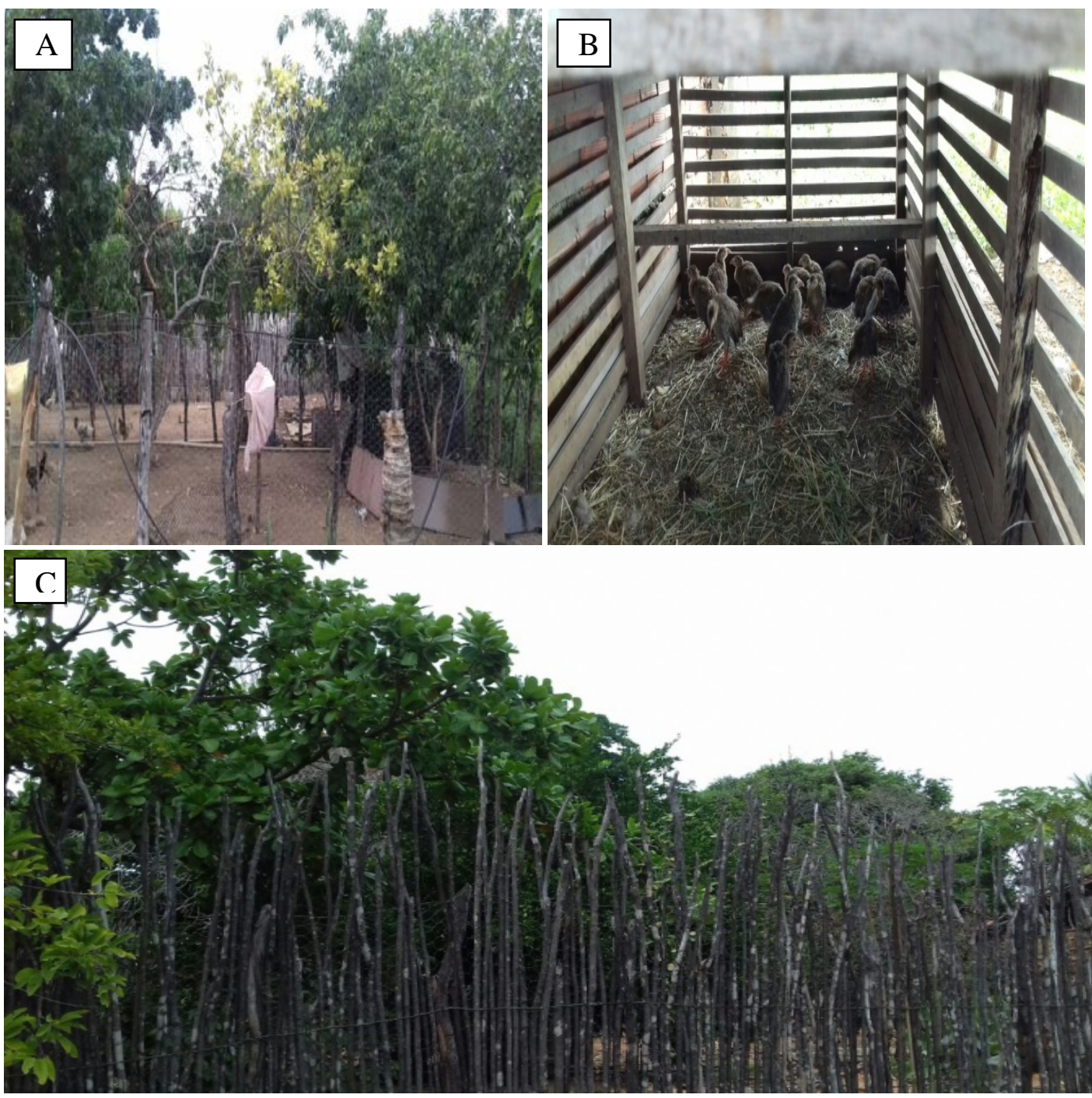

Figura 6. Cerca de tela para proteger as plantas dos animais (A); Cercado de tábua para proteger as plantas dos animais (B); Cerca de vara para proteger as plantas dos animais (C).

Analisando todo o cultivo agrícola, as fruteiras são as espécies predominantes nos quintais. Como aspectos contrastantes a outros trabalhos se verificou a ocorrência de poucos exemplares de plantas medicinais e também a ausência de plantas ornamentais, para os quais os quintais são considerados um sistema ideal para suprir as necessidades das famílias (Gazel Filho, 2008).

De acordo com $75 \%$ dos entrevistados as plantas que mais gostariam de plantar no seu quintal foram banana, abacate, graviola, cajarana, pinha, coco, fava, mamão, caju, acerola, romã, goiaba e cajá, $20 \%$ se mostrou satisfeito e $5 \%$ não tem interesse em acrescentar nenhuma nova espécie. Chitsondzo e Silva (2013) apesar dos quintais apresentarem muitas espécies comuns (repetidas) muitos ainda gostariam de introduzir novas espécies por conta do valor comercial e a necessidade de suprimento alimentar.

\section{Manejo}

Houve uma clara divisão de tarefas com base nas relações de gênero, em 90\% dos entrevistados cabe ao homem às atividades que demanda maior força, como o preparo do terreno para o plantio, 
capinar, adubar, irrigar, cercar, seja revirando o solo ou cavando covas. As mulheres participam geralmente da colheita, a qual não precisa muito esforço. De acordo com a pesquisa 35\% o homem foi responsável pelo manejo com ajuda da mulher para colheita, $20 \%$ a mulher ajudou ao homem no manejo e na colheita, 10\% a própria mulher cuida do manejo e da colheita, $10 \%$ o homem cuida da plantação com a mulher e dois filhos cuidam dos animais, $10 \%$ um homem e um filho cuidam do manejo e a mulher da colheita, $10 \%$ o homem, mulher e filho cuidam juntos do manejo e da colheita, 5\% apenas a homem cuida do manejo e o filho ajuda na colheita. Muitas vezes existe uma ação cooperativa entre vizinhos no preparo do solo, plantio e colheita. Estas informações são semelhantes a Chitsondzo e Silva (2013) e Salim (2012) em que no levantamento das atividades praticadas pelos produtores, observou-se que a agricultura está presente em todos os quintais, sendo que em $100 \%$ as mulheres estão presentes nas tarefas de manejo e colheita.

Com base no manejo de pragas, $25 \%$ dos questionários aplicados mostraram que os proprietários não utilizam nenhum tipo de insumo externo e $75 \%$ utilizam três diversidades, como, fertilizante e agrotóxicos e veneno para matar formigas. Sendo que 35\% usam somente fertilizantes (Figura 7). As plantas que nascem espontaneamente recebem tratamentos diferenciados. Para que a planta permaneça no quintal ela vai depender de sua espécie, o que, no entanto mostra que, 93\% são descartadas e 7\% são feitas as mudas ou dependendo do local onde nasceu, permanece. Os dados apresentados demonstram que os produtores possuem técnicas, habilidade e conhecimento adequado para enfrentar cada situação diferenciada que venha aparecer no seu quintal, como na utilização de árvores e arbustos em associação com a produção agrícolas e/ou pecuária.

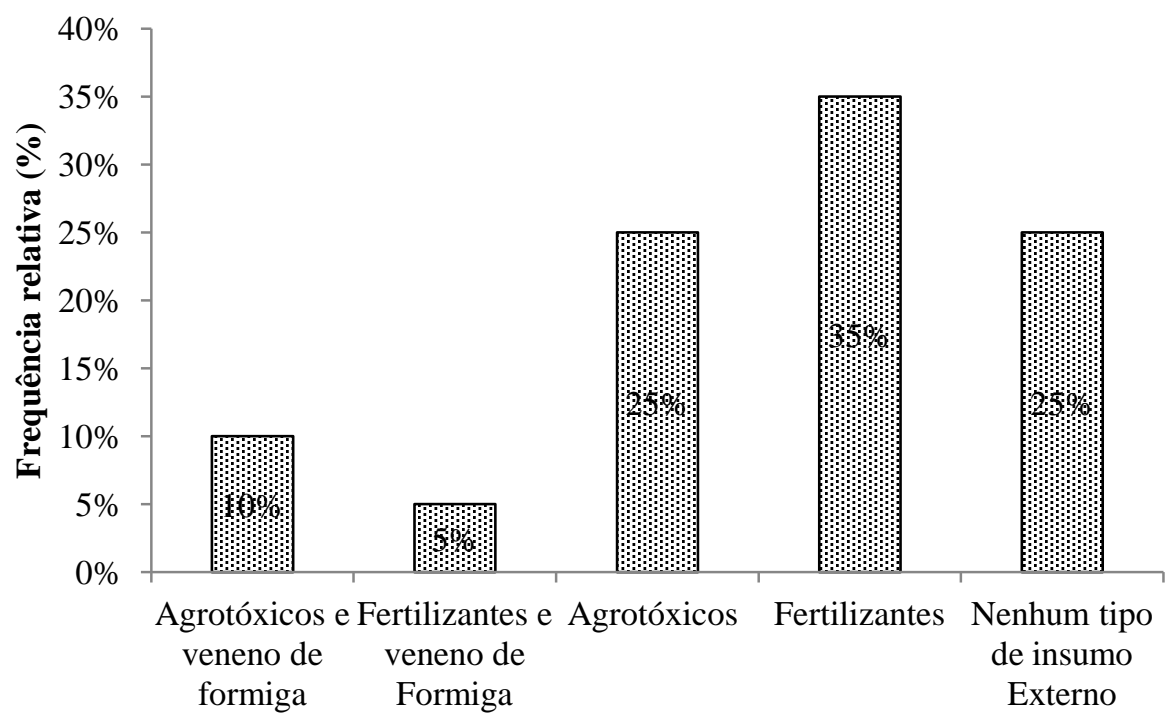

Figura 7. Frequência relativa do uso de insumo externo.

No manejo com os vegetais são desenvolvidas as seguintes práticas: preparação do solo para algumas espécies como (feijão, fava e milho), capinação que inclui a parte da limpeza, fertilização, controle de pragas, irrigação e adubação, onde $60 \%$ dos entrevistados utilizam esterco animal como adubo. Já com os animais são desenvolvidas as seguintes práticas: a alimentação, sendo colocada 
para cada espécie a ração adequada, água, remédios, limpeza dos locais onde ficam reservados, abatimento, retirada de leite em bovinos e prisão das espécies ovinas e bovinas o que muitos dizem "chiqueirar" e "colocar em curral" (Figura 8).

Segundo Tonini (2013) As práticas com o plantio agrícola e a criação de animal mostram-se alternativas de diversificação e sustento das famílias. As práticas de manejo adequadas favorecem a diversificação da produção e a agrobiodiversidade do grupo familiar, agregando maior segurança alimentar e estabilidade financeira aos agricultores.
A infraestrutura para confinamento de animais é construída de forma precária e a partir de material local, que no caso do confinamento dos ovinos e suínos consiste em uma cerca de vara colocando algumas estacas sem coberta, com exceção das vacas que são confinadas apenas a noite, resultado semelhante ao de Chitsondzo e Silva (2013) em um estudo que tinha como objetivo caracterizar e avaliar os quintais caseiros em Machipanda, distrito de Manica (Moçambique),onde estes autores verificaram as formas precárias na infraestrutura para confinamento dos animais.
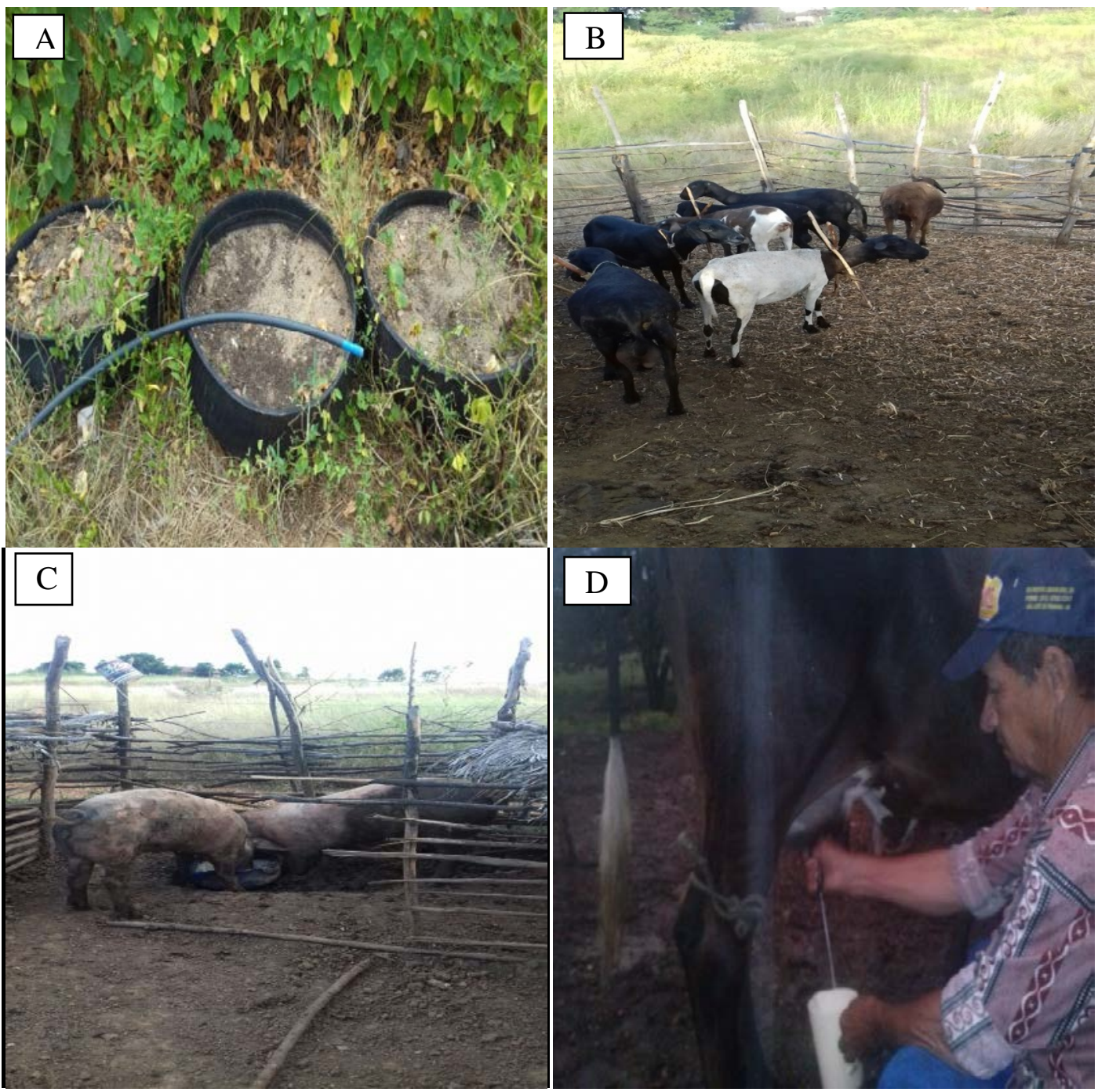

Figura 8. Práticas de irrigação e adubação com esterco animal para o plantio (A); Curral de vara para confinamento de ovinos (B); Curral para confinamento de suínos (C); Ordenha de vacas (D). 
Os restos alimentares produzidos pela família são colocados para os porcos. A família que não criam os porcos, juntam os restos alimentares para os porcos de outro vizinho, reduzindo assim os gastos com ração e contribuindo na renda familiar (Figura 9).

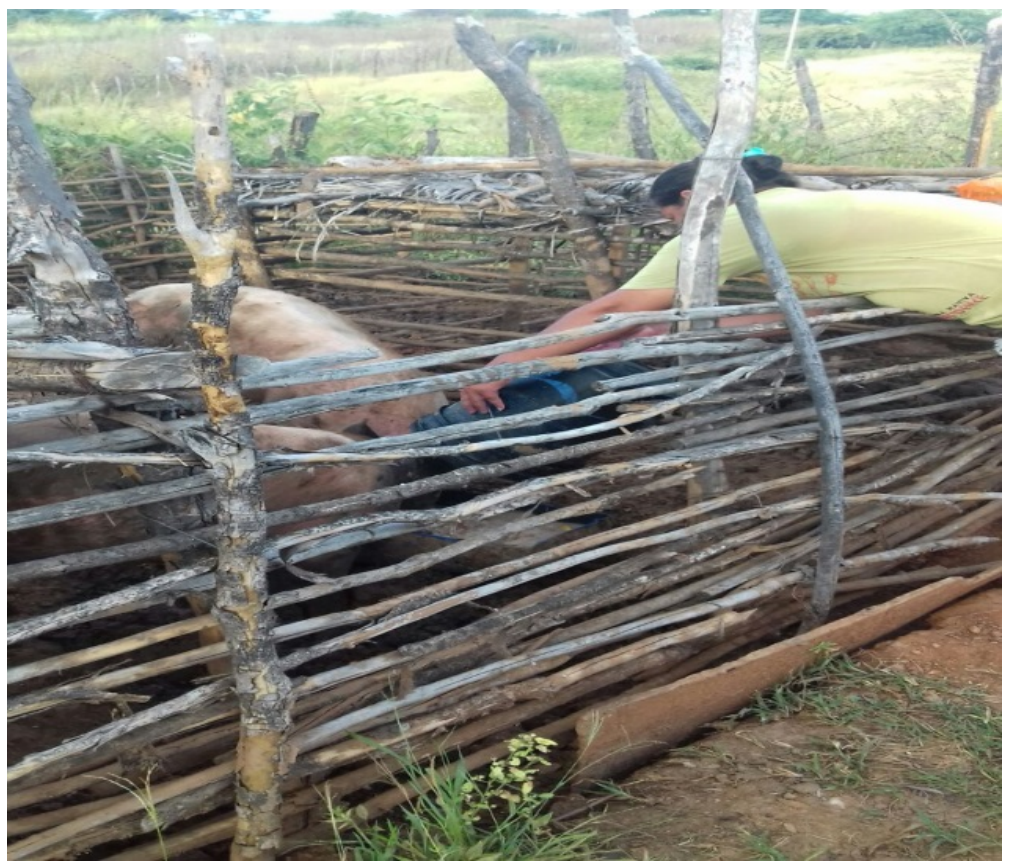

Figura 9. Criação de suínos através de restos de alimentos.

No decorrer do tempo, as árvores perdem as folhas e galhos, que ao cair são dispersos no quintal. Para lidarem com esse fenômeno os produtores responderam ter alguns comportamentos diferentes, onde responderam 35\% dos produtores retirarem esses galhos do quintal, $30 \%$ queimarem, $20 \%$ varrerem para os troncos, $10 \%$ deixarem no mesmo local, $5 \%$ enterrarem próximo às plantas. Resultado diferente dos encontrados por Beretta (2010) na sua pesquisa, sobre a flora dos quintais agroflorestais de Ibiraquera, Imbituba, SC: expressões ambientais e culturais, em que $100 \%$ dos galhos são utilizados na queima em fogão a lenha.

Muitas famílias necessitam de uma renda gerada a partir do que é produzido no seu quintal, em que para isso dizem necessitar de maiores facilidades, como: um espaço maior, água em quantidade suficiente, assistência técnica e mais tempo para dedicar a essa atividade, citando a água como principal fonte, sendo que na época chuvosa a demanda de produtos é bem maior por conta da obtenção de água para irrigação. Segundo Florentino et al. (2007), essa maior demanda de produtos é bem maior devido à facilidade na obtenção de água para irrigar as plantações e à ação direta das chuvas.

\section{Espécies presentes no quintal}

Espécies presentes, plantadas ou nascidas ao acaso (nome popular e científico) o que sintetiza as principais características observadas nos quintais estão expressas na Tabela 1. 
Tabela 1. Espécies presentes nos quintais.

\begin{tabular}{|c|c|}
\hline Nome popular na localidade & Nome científico \\
\hline Abacate & Persea americana \\
\hline Abóbora & Cucurbita pepo \\
\hline Acerola & Malpighia emarginata \\
\hline Alecrim & Rosmarinus officinalis \\
\hline Alfazema & Lavandula angustifolia \\
\hline Algaroba & Prosopis juliflora \\
\hline Algodão & Gossypium hirsutum \\
\hline Anador & Justicia pectoralis \\
\hline Babosa & Aloe vera \\
\hline Banana & Musa spp \\
\hline Batata doce & Ipomoea batatas \\
\hline Cana-de-açúcar & Saccharum officinarum \\
\hline Cajá & Spondias mombin \\
\hline Cajarana & Spondias lutea \\
\hline Caju & Anacardium occidentale \\
\hline Capim-santo & Cymbopogon citratus \\
\hline Carambola & Averrhoa carambola \\
\hline Castanhola & Terminalia catappa \\
\hline Ciriguela & Spondias purpurea \\
\hline Coco & Cocos nucifera \\
\hline Coentro & Coriandrum sativum \\
\hline Endro & Anethum graveolens \\
\hline Erva cidreira & Melissa officinalis \\
\hline Fava & Phaseolus lunatus \\
\hline Feijão & Phaseolus vulgaris \\
\hline Goiaba & Psidium guajava \\
\hline Graviola & Annona muricata \\
\hline Hortelã & Mentha sp \\
\hline Juazeiro & Ziziphus joazeiro \\
\hline Laranja & Citrus sinensis \\
\hline Limão & Citrus limon \\
\hline Malva corama & Bryophyllum pinnatum \\
\hline Malva-do-reino & Plectranthus amboinicus \\
\hline Mamão & Carica papaya \\
\hline Mandioca & Manihot esculenta \\
\hline Manga & Mangifera indica \\
\hline Manjericão & Ocimum basilicum \\
\hline Melancia & Citrullus lanatus \\
\hline Mentruz & Dysphania ambrosioides \\
\hline Milho & Zea mays \\
\hline Mulungú & Erythrina velutina \\
\hline Palma & Opuntia ficus-indica \\
\hline Pau ferro & Libidibia ferrea \\
\hline Pinha & Annona squamosa \\
\hline Romã & Punica granatum \\
\hline Tamarindo & Tamarindus indica \\
\hline Tangerina & Citrus reticulata \\
\hline
\end{tabular}


As espécies de animais mais presentes nos quintais foram: galinhas e suínos, constituindo um percentual de $75 \%$ criadores de galinhas e $25 \%$ de suínos, sendo que outras espécies são criadas na localidade como as vistas na Tabela 2.

Tabela 2. Percentual, finalidade e manejo de animais.

\begin{tabular}{|c|c|c|c|c|}
\hline \multicolumn{2}{|l|}{ Animais } & $\begin{array}{c}\text { Percentual } \\
\text { de criadores }\end{array}$ & Finalidade & Manejo \\
\hline \multirow{2}{*}{ Aves } & Galinhas & $75 \%$ & Consumo e comércio & $\begin{array}{c}\text { Limpeza no terreno, ração, } \\
\text { água e medicação. }\end{array}$ \\
\cline { 2 - 5 } & Peru & $5 \%$ & Consumo & $\begin{array}{c}\text { Limpeza no terreno, ração, } \\
\text { água e medicação. }\end{array}$ \\
\cline { 2 - 5 } & Capote & $10 \%$ & Consumo e comércio & $\begin{array}{c}\text { Limpeza no terreno, ração, } \\
\text { água e medicação. }\end{array}$ \\
\hline \multicolumn{2}{|c|}{ Bovinos } & $15 \%$ & Consumo e comércio & $\begin{array}{c}\text { Ração, água, medicação e } \\
\text { prisão a noite. }\end{array}$ \\
\hline Suínos & $25 \%$ & Consumo e comércio & $\begin{array}{c}\text { Limpeza no terreno ração, } \\
\text { água e medicação. }\end{array}$ \\
\hline Peixes & $5 \%$ & Consumo e comércio & $\begin{array}{c}\text { Ração e biometria a cada } 30 \\
\text { dias. }\end{array}$ \\
\hline Ovinos & $15 \%$ & Consumo e comércio & $\begin{array}{c}\text { Ração, água, medicação e } \\
\text { prisão a noite. }\end{array}$ \\
\hline Gato & $15 \%$ & Estimação & Ração, água e medicação. \\
\hline Cachorro & $10 \%$ & Estimação & Ração, água e medicação. \\
\hline
\end{tabular}

Na plantação, $85 \%$ dos produtores agrícolas não incorporaram nenhuma espécie nova nos últimos anos, os outros $15 \%$ incorporaram três novas espécies: graviola, bananeira e acerola. Sendo que $30 \%$, dos $85 \%$, que não incorporaram nenhuma espécie deixaram de plantar a fava por conta das longas estiagens nos últimos anos. 0 fato que $100 \%$ dos entrevistados notaram a diminuição da produção do cultivo em geral, afetando principalmente a goiabeira. Entre as espécies citadas na Tabela 1 encontram-se três espécies que são plantadas anualmente por $70 \%$ dos produtores, entre elas estão: milho, fava e feijão, numa medida que varia de $0,5 \mathrm{~kg}$ a $2,5 \mathrm{~kg}$. Em que $35,8 \%$ plantam $0,5 \mathrm{~kg}, 28,6 \%$ plantam $1,0 \mathrm{~kg}, 21,4 \%$ plantam $1,5 \mathrm{~kg}, \quad 7,1 \%$ plantam 2,0 kg e 7,1\% plantam 2,5 kg variando de quintal para quintal, dependendo do tamanho de sua área territorial. Segundo Gazel Filho (2008), no seu trabalho sobre composição, estrutura e função de quintais agroflorestais no Município de Mazagão, Amapá, os quintais estão estruturados de acordo com sua extensão.

Quanto à produtividade, os produtores citaram que apenas três espécies produzem o ano todo, entre elas estão: a bananeira, o coqueiro e o mamoeiro. E uma produz mais de uma vez ao ano (acerola) e as demais não produzem o ano todo (Tabela 3).

Com relação às espécies cultivadas, a Tabela 4 mostra seus fins. Apesar das finalidades apresentadas muitas das espécies são consumidas pela própria família e comercializas para ajudar na renda da família. 0 que tem mostrado importância econômica, e que para muitos tem sido considerado como principal fonte de renda. 
Tabela 3. Produção das espécies ao ano.

\begin{tabular}{|c|c|}
\hline Cultivo & Periodicidade \\
\hline Abacate & Não produz o ano todo \\
\hline Abóbora & Não produz o ano todo \\
\hline Acerola & Produz mais de uma vez por ano \\
\hline Alecrim & Não produz o ano todo \\
\hline Alfazema & Não produz o ano todo \\
\hline Algaroba & Não produz o ano todo \\
\hline Algodão & Não produz o ano todo \\
\hline Anador & Não produz o ano todo \\
\hline Babosa & Não produz o ano todo \\
\hline Banana & Produz o ano todo \\
\hline Batata doce & Não produz o ano todo \\
\hline Cana-de-açúcar & Não produz o ano todo \\
\hline Cajá & Não produz o ano todo \\
\hline Cajarana & Não produz o ano todo \\
\hline Caju & Não produz o ano todo \\
\hline Capim-santo & Não produz o ano todo \\
\hline Carambola & Não produz o ano todo \\
\hline Castanhola & Não produz o ano todo \\
\hline Ciriguela & Não produz o ano todo \\
\hline Coco & Produz o ano todo \\
\hline Coentro & Não produz o ano todo \\
\hline Endro & Não produz o ano todo \\
\hline Erva cidreira & Não produz o ano todo \\
\hline Fava & Não produz o ano todo \\
\hline Feijão & Não produz o ano todo \\
\hline Goiaba & Não produz o ano todo \\
\hline Graviola & Não produz o ano todo \\
\hline Hortelã & Não produz o ano todo \\
\hline Juazeiro & Não produz o ano todo \\
\hline Laranja & Não produz o ano todo \\
\hline Limão & Não produz o ano todo \\
\hline Malva corama & Não produz o ano todo \\
\hline Malva do reino & Não produz o ano todo \\
\hline Mamão & Produz o ano todo \\
\hline Mandioca & Não produz o ano todo \\
\hline Manga & Não produz o ano todo \\
\hline Manjericão & Não produz o ano todo \\
\hline Melancia & Não produz o ano todo \\
\hline Mentruz & Não produz o ano todo \\
\hline Milho & Não produz o ano todo \\
\hline Mulungú & Não produz o ano todo \\
\hline Palma & Não produz o ano todo \\
\hline Pau ferro & Não produz o ano todo \\
\hline Pinha & Não produz o ano todo \\
\hline Romã & Não produz o ano todo \\
\hline Tamarindo & Não produz o ano todo \\
\hline Tangerina & Não produz o ano todo \\
\hline
\end{tabular}


Tabela 4. Finalidade produtiva das espécies cultivadas.

\begin{tabular}{|l|l|}
\hline \multicolumn{1}{|c|}{ Finalidade } & \multicolumn{1}{c|}{ Espécies cultivadas } \\
\hline Alimentação humana & $\begin{array}{l}\text { Abacate, abóbora, acerola, banana, batata doce, } \\
\text { cana-de-açúcar, cajá, cajarana, caju, carambola, } \\
\text { ciriguela, coco, coentro, fava, feijão, goiaba, } \\
\text { graviola, laranja, limão, mamão, mandioca, } \\
\text { manga, melancia, milho pinha, tamarindo e } \\
\text { tangerina. }\end{array}$ \\
\hline Alimentação animal & Milho, algaroba, cana-de-açúcar e palma. \\
\hline Medicinal & $\begin{array}{l}\text { Alecrim, alfazema, anador, capim-santo, endro, } \\
\text { erva cidreira, hortelã, malva corama, malva do } \\
\text { reino, manjericão, mentruz e romã. }\end{array}$ \\
\hline Outros & Algodão, babosa, castanhola, juá e pau ferro. \\
\hline
\end{tabular}

As plantas que foram encontradas nos quintais são usadas para diversos fins. Apesar de todas as espécies serem consideradas úteis, foi observado que um pequeno número é utilizado para mais de uma finalidade, o resultado encontrado coincide com Florentino et al. (2007) na pesquisa sobre, contribuição de quintais agroflorestais na conservação de plantas da Caatinga, Município de Caruaru, Estado de Pernambuco, Brasil.

\section{Considerações finais}

Os quintais agroflorestais da comunidade pesquisada tem um papel relevante para as famílias, onde tem contribuído na sua alimentação e renda. Podendo observar que as mulheres estão presentes em todas as lidas com o quintal.

A escassez hídrica tem sido uma das maiores dificuldades para a estruturação do quintal, devido à falta de chuva nos últimos anos. Muitos dos agricultores que não tinham acesso à água tiveram que furar poços tubulares para manter a produtividade. Já para algumas famílias a solução foi diminuir o tamanho do quintal. 0 quintal dentre muitos usos têm se destacado o plantio agrícola e a criação de animais, contribuindo na renda familiar, diminuindo gastos e obtendo lucros.

A produção para o autoconsumo predomina, deixando uma menor parte para a comercialização e consumo animal.
Ainda que configurando a produtividade como fator de renda indireta, tem sido uma alternativa de diminuir gastos.

Os quintais apresentaram uma composição diversificada. No que se refere ao uso das espécies fruteiras, medicinais, alimentares e outros usos, as fruteiras são altamente predominantes. Quanto às espécies de animais, os mais presentes são as galinhas e os porcos.

Ao estudar os aspectos funcionais e estruturais dos quintais, pode-se observar de forma semelhante que as plantações estão localizadas de forma junto às residências precisamente nos fundos dos terrenos, tanto para o cultivo, como para a criação de animais, sendo que as plantas são protegidas dos animais com cercas de varas, madeiras e telas de arames, facilitando o manejo e a proteção do cultivo.

Além de colaborar com a busca da segurança alimentar, os quintais são espaços de preservação do conhecimento tradicional, em que cada morador desenvolve uma maneira diferenciada de cuidar e utilizar os arredores de sua casa, em que esses usos dos espaços dos quintais produtivos tornam-se tradicionais no sentido de que são herdados e mantidos pelas gerações posteriores, destacando a relevância e valor cultural desses locais para as tradições na preservação da história local e laços culturais da comunidade. 


\section{Conflito de interesses}

Os autores declaram não haver conflito de interesses.

\section{Referências}

Almeida, S.; Gama, J. R. V. Quintais agroflorestais: estrutura, composição florística e aspectos socioambientais em área de assentamento rural na Amazônia brasileira. Ciência Florestal, v. 24, n. 4, p. 1041-1053, 2014. https://doi.org/10.1590/1980509820142404023

Araujo, J. T.; Barros, J. D. S.; Pordeus, A. V.; Moreira, R. S.; Silva, J. L. A. Socioeconomic and technological analysis of resident population surrounding the São Gonçalo permanent preservation area in the Municipality of Sousa, State of Paraíba, Brazil. International Journal of Development Research, v.7, n. 6, p. 1301913021, 2017.

Barros, J. D. S.; Chaves, L. H. G.; Farias, S. A. R. Aspectos socioeconômicos na Microbacia Hidrográfica do Riacho Val Paraíso-PB - Brasil. REDES - Revista de Desenvolvimento Regional, v. 19, n. 1, p. 169-187, 2014. https://doi.org/10.17058/redes.v19i1.3904

Beretta, M. E. A flora dos quintais agroflorestais de Ibiraquera, Imbituba, SC: expressões ambientais e culturais. Florianópolis: Universidade Federal de Santa Catarina, 2010. (Dissertação de mestrado).

Chitsondzo, C. C. E.; Silva, I. C. Quintais caseiros em Machipanda, Distrito de Manica, Moçambique. Pesquisa Florestal Brasileira, $\begin{array}{llll}\text { v. } 33, & \text { p. } 74, & \text { p. } 127-135,\end{array}$ https://doi.org/10.4336/2013.pfb.33.74.413

CPRM - Serviço Geológico do Brasil. Projeto cadastro de fontes de abastecimento por água subterrânea: diagnóstico do Município de São José de Piranhas, Estado da Paraíba. Recife: CPRM/PRODEEM, 2005.

Damaceno, J. B. D.; Lobato, A.C. N. Caracterização de um quintal agroflorestal na Amazônia Central, Brasil. Revista Brasileira de Gestão Ambiental e Sustentabilidade, v. 6, n. 12 , p. 163-173, 2019. https://doi.org/ $10.21438 /$ rbgas.061214

Florentino, A. T. N.; Araújo, E. L.; Albuquerque, U. P. Contribuição de quintais agroflorestais na conservação de plantas da Caatinga, Município de Caruaru, PE, Brasil. Acta Botanica
Brasilica, v. 21, n. 1, p. 37-47, 2007. https://doi.org/10.1590/S0102-33062007 000100005

Freitas, J. L. Sistemas agroflorestais e sua utilização como instrumento de uso de terra: o caso dos pequenos agricultores da Ilha de Santana, Amapá, Brasil. Belém: Universidade Federal Rural da Amazonas e Embrapa, 2008. (Tese de doutorado).

Gazel Filho, A. B. G. Composição, estrutura e função de quintais agroflorestais no Município de Mazagão, Amapá. Belém: Universidade Federal Rural da Amazônia e Embrapa Amazônia Oriental, 2008. (Tese de doutorado).

Gervazio, W. Agrobiodiversidade e qualidade do solo em quintais agroflorestais urbanos na Cidade de Alta Floresta-MT. Alta Floresta: Universidade do Estado de Mato Grosso, 2015. (Dissertação de mestrado).

Gomes, G.S. Quintais agroflorestais no município de Irati-Paraná, Brasil: agrobiodiversidade e sustentabilidade socioeconômica e ambiental. Curitiba: Universidade Federal do Paraná, 2010. (Tese de doutorado).

Gonçalves, J. P.; Lucas, F. C. A. Agrobiodiversidade e etnoconhecimento em quintais de Abaetuba, Pará, Brasil. Revista Brasileira de Biociência, v. 15, n. 3, p. 119134, 2017

Laranjeira, D. B.; Magalhães, T. S. S.; Souza, D. A.; Simas, K. S.; Laranjeira, L. S. Quintais agroflorestais: uma iniciativa de convivência com o Semiárido. Enciclopédia Biosfera, v. 11, n. 20, p. 133-141, 2015.

Pinto, I. C. Agrobiodiversidade em quintais agroflorestais urbanos e perfil social de etnias em São Gabriel da Cachoeira-AM. Lavras: Universidade Federal de Lavras, 2012. (Tese de doutorado)

Salim, M. V.C. Quintais agroflorestais em área de terra-firme na Terra Indígena Kwatá-Laranjal, Amazonas. Manaus: Instituto Nacional de pesquisas da Amazônia, 2012. (Dissertação de mestrado).

Santos, E. G.; Santos, S. S.; Gonçalves, V. N.; Souza, B. I.; Lucena, R. F. P. Utilização de recursos vegetais em áreas de quintais em uma comunidade rural localizada no entorno do Parque Nacional de Sete Cidades, Piauí, Nordeste do Brasil. Revista Brasileira de 
Gestão Ambiental e Sustentabilidade, v. 6, n. 13, p. 365-383, 2019. https://doi.org/ $10.21438 /$ rbgas.061308

Silva, R. L.; Leite, M. F. A.; Santos, A. S.; Azevedo, A. L.; Oliveira, A. S.; Silva, A. E. Agrobiodiversidade em quintais agroflorestais urbanos de três municípios da região sul do Amazonas, Brasil. Caderno de Agroecologia, v. 13, n. 1, p.1-7, 2018. Disponível em: <http://cadernos.aba-agroecologia.org.br/ index.php/cadernos/article/view/285>. Acesso em: 23 abr. 2019.

Silva, E. L.; Menezes, E. M. Metodologia da pesquisa e elaboração de dissertação. Florianópolis: UFSC, 2005.
Sousa, D. A.; Oliveira, A. A.; Conceição, G. M. Agrobiodiversidade em quintais familiares no Município de Caxias, Maranhão. Enciclopédia Biosfera, v. 10, n. 18, p. 3129-3139, 2014.

Tonini, R. T. Agrobiodiversidade e quintais agroflorestais como estratégias de autonomia em assentamento rural. Viçosa: Universidade Federal de Viçosa, 2013. (Dissertação de mestrado).

Vieira, T. A.; Rosa, L. S.; Santos, M. M. L. S. Agrobiodiversidade de quintais agroflorestais no Município de Bonito, Estado do Pará. Revista de Ciências Agrárias, v. 55, n. 3, p. 159-166, 2012.

(CC) Attribution, que permite uso irrestrito, distribuição e reprodução em qualquer meio, desde que a obra original seja devidamente citada. 